Simion, M. (2019) Conceptual engineering for epistemic norms. Inquiry, (doi: 10.1080/0020174X.2018.1562373)

There may be differences between this version and the published version. You are advised to consult the publisher's version if you wish to cite from it.

http://eprints.gla.ac.uk/172291/

Deposited on 1 November 2018

Enlighten - Research publications by members of the University of Glasgow http://eprints.gla.ac.uk 


\title{
Conceptual Engineering for Epistemic Norms
}

\begin{abstract}
What makes an epistemic norm distinctively epistemic? According to the received view in the literature, if a norm $\mathrm{N}$ regulates the epistemic properties required for permissibly phi-ing, then $\mathrm{N}$ is an epistemic norm.

This paper is involved in conceptual engineering. It has two aims: first, it argues that the received view should be abandoned, in that it fails to identify epistemic and only epistemic requirements, and it misses fit with the general normative landscape. At the same time, I argue, the failure of the received view is no reason for skepticism about 'the epistemic' as a sui generis normative domain.

This paper's second and central aim is an ameliorative aim: it proposes a novel approach to individuating epistemic norms. In a nutshell, according to the ameliorative proposal I will develop here, epistemic norms are to be individuated by their association with distinctively epistemic values.
\end{abstract}




\section{Introduction}

Epistemic concepts such as knowledge and evidence figure prominently in our everyday evaluations of each other's actions and mental states. It often comes natural to say things like: 'Why would you believe such a thing? You have no evidence that that's the case!, or to challenge assertions with 'How do you know?' questions. Moreover, there is a widespread consensus among epistemologists that there are distinctively epistemic norms that underwrite these evaluations. For instance, many think that there is are epistemic norms telling us to believe only what we have evidence for and to assert only what we know.

This raises the question as to what makes an epistemic norm distinctively epistemic, as opposed to say, moral, prudential, aesthetic, etc.? It is fair to say that the most widely accepted answer to this question is that if a norm regulates the epistemic properties required for permissibly phi-ing, then it's an epistemic norm. Let's call this view CONTENT INDIVIDUATION (CI). ${ }^{1}$

At the same time, not everyone is on board with CI. What's interesting is that, among recent critics of the view, the perhaps most prominent view is eliminativism about the epistemic. Roughly, the thought here is that there is no satisfactory answer to be found to the question as to what makes a purportedly epistemic norm distinctively epistemic and that, as a

\footnotetext{
${ }^{1}$ See e.g. (Benton 2014), (Brown 2010), (Maitra 2011), (Lackey 2013), (Gerken 2014); see also Section \#4 for discussion.
} 
result, the thing to do is simply remove the term 'epistemic' from the philosophical lexicon, at least as a modifier of norms. ${ }^{2}$

In previous work, I have extensively argued ${ }^{3}$ for two descriptive claims: (1) That CI is extensionally inadequate, and (2) that (1) gets us in trouble in several debates in epistemology and beyond. This paper is a paper involved in conceptual engineering; ${ }^{4}$ it abandons the descriptive project and takes on an ameliorative approach to the question as to what makes an epistemic norm distinctively epistemic. This ameliorative approach shares the pessimism of eliminativists about CI and the optimism of champions of CI about distinctively epistemic norms. It argues that our technical term 'epistemic norm' will be perfectly able to pick out a respectable normative category once we abandon CI as individuation procedure. In a nutshell, according to the proposal I will develop here, epistemic norms should be individuated by their association with distinctively epistemic values. What makes a norm a distinctively epistemic

\footnotetext{
2 See e.g. (Hazlett 2016): "I argue that "epistemic" is ambiguous: it is sometimes used to mean "of or relating to knowledge" and sometimes to mean "of or relating to belief." I raise some worries about this ambiguity, and sympathetically consider the prospects for eliminating "epistemic" from our philosophical lexicon.' See also (Cohen 2016) and section \#3 for discussion.

${ }^{3}$ See e.g. (Author 2016, 2018a, 2018b, 2018c, Forthcomingb).

${ }^{4}$ In line with projects by, among others, people like Sally Haslanger (2000), Herman Cappelen (forthcoming), Matti Eklund (2015), Patrick Greenough (In Progress) and Kevin Sharp (2013).
} 
norm is the fact that it is associated with an epistemic value. Call this view VALUE INDIVIDUATION (VI).

Here is a game plan for the remainder of this paper: Section \#2 motivates the need for an individuation criterion. In Section \#3 I identify a set of desiderata for a satisfactory way to individuate epistemic norms. Section \#4 takes a closer look at CI and argues that it fails as it does not satisfy a number of the relevant desiderata. In Section \#5, I introduce VI and argue that this view does satisfy the relevant desiderata. Finally, in the last section (\#6), I conclude.

\section{Why Care?}

Consider the term 'moral'. It's no exaggeration to say that this term is reasonably well understood even among non-philosophers and that we competently deploy it frequently. Just note how often we say things like 'That's immoral' or 'The morally right thing to do is such-and-so,' etc.

In this respect there is an important difference between the term 'moral' and the term 'epistemic'. The latter is neither well understood even among non-philosophers nor is it competently deployed very frequently. We don't say things like 'That's unepistemic' or 'The epistemically right belief to form here is such-and-so,' etc. Unlike 'moral', 'epistemic' is (still) philosophers' jargon. 
One important consequence of this is that the need for a criterion for individuating type-specific norms is particularly pressing in the case of epistemic norms. Of course, it would be nice to have a precise criterion for what makes a certain norm a distinctively moral norm. Even so, it may be less pressing here since we have some independent handle on the issue thanks to our understanding of the term 'moral'. What's more, we can use intuitions about when 'moral'/'not moral' are correctly applicable, which embody this understanding, in an effort to (at least partly) reverse engineer a relevant criterion. In contrast, in the case of 'epistemic' we don't have an independent handle on the issue, or at least not an equally good one. Likewise, we have considerably less reason to be optimistic about a reverse engineering project.

Of course, this is not to say that we cannot use intuition at all. For instance, it seems pretty clear that the norm that one ought to change a flat tire on one's car is not an epistemic norm. Rather, the point here is that while the meaning of 'moral' may well be sufficiently settled to delineate a class of distinctively moral norms, the same is not true of 'epistemic'. By the same token, the onus is still on us epistemologists to delineate a class of epistemic norms with sufficient clarity. There is a particularly pressing need for an individuation criterion here.

Furthermore, note that even if one is a sceptic about epistemic normativity per se, it is undeniable that 'epistemic norms' exist as a technical term: philosophers have been debating over the correct 'epistemic norm' for belief, judgment, practical 
reasoning, action, assertion, telling, explaining for several decades already. Here is Stew Cohen (who credits Jessica Brown for this objection):

Perhaps technical expressions can have more in common with natural language expressions than I am allowing. How do natural language expressions get their meaning? Certainly, a large part of the story is that they acquire their meaning by being used in a particular way by a community of speakers. Can we say that a technical term like 'epistemic' acquires its meaning by being used in a particular way by a very specialized community--the community of epistemologists? If so, then when epistemologists talk about epistemic justification, what they are talking about is determined by how they have been using that expression $(2016,7)$.

Even if one doubts the normative force of the epistemic domain, then, there is still pressing need to get clear on what we are talking about (or in the business of talking about) when we talk about epistemic norms. Indeed, sceptics themselves need a clearly defined technical notion of 'epistemic norm' in order to even get started in the business of denying that the technical term maps on to anything in the normative landscape proper.

This need is further exacerbated by the fact that, without a clear individuation criterion, epistemologists might end up 
talking past each other when the debate such things as epistemic justification, the epistemic norm of assertion, etc. This worry has been voiced by Jennifer Lackey in connection to the epistemic norm of assertion:

For now, whenever evidence is adduced that concerns the epistemic authority requisite for proper assertion, it may bear on the norm of assertion or it may bear on these other $[\ldots]$ norms. $[\ldots][1] \mathrm{t}$ will be extremely difficult, if not impossible, to tell which is being defended (Lackey 2011, 277).

Consider, also, Stewart Cohen's (admittedly somewhat more general) worry about this issue:

[E]pistemologists' use of the term 'epistemic' has led to serious confusion in the discussion of epistemological issues. The source of the problem is that 'epistemic' functions largely as an undefined technical term. [T]his confusion has infected discussions of the nature of epistemic justification, epistemic norms for evidence gathering, and knowledge norms for assertion and belief $(2016,839)$.

These considerations all highlight that giving a clear enough criterion for individuating epistemic norms (or 'epistemic norms') 
is a task we epistemologist need to tackle with some degree of urgency.

\section{Desiderata}

Now that we have a good understanding of just why we need an individuation criterion for distinctively epistemic norms, let's ask what makes a candidate criterion a good one? I'd like to propose the following desiderata.

1. INDEPENDENCE. We want the criterion to delineate a class of norms that is independent from other classes of norms.

2. GENERALITY. We want our criterion to be generalizable, in the sense that it can, after normative-domain-relative interventions, be employed not only serve to delineate distinctively epistemic norms but also distinctively moral norms, prudential norms, etc.

3. THEORETICAL ADEQUACY. We want our individuation recipe to accommodate properties of type-specific norms that are widely recognized in the general theory of normativity. What's more, we'd want this to be the case not only for the specific criterion for epistemic norms but also for the generalized version of it (by GENERALITY). 
4. INTUITIVE ADEQUACY. Finally, we want the criterion to be extensionally adequate in the sense that it makes correct classifications: ideally, we want it to successfully capture our intuitions when it comes to classifying all epistemic norms as epistemic and all non-epistemic norms as non-epistemic. Also, again, we want this to be the case not only for specifically epistemic norms but (by GENERALITY) also for other types of norms (prudential, moral, etc.). To repeat, since our handle on the meaning of 'epistemic' is less than perfect, we'll have to proceed with care. That said, there do appear to be some clear-cut cases. For instance, whatever the individuation recipe we come up with for epistemic norms, it should better not classify 'One ought to change a flat tire on one's car!' as an epistemic norm. What's more, in cases involving at least some non-epistemic norms, e.g. moral ones, we have a better handle on the meaning and so we may be better positioned to make the relevant verdicts.

5. THEORY NEUTRALITY. We want our individuation recipe to be theory neutral; that is, we do not want to individuate the epistemic in such a way as to, for instance, only vindicate epistemic externalism; rather, what we need is for epistemic normativity, whatever it turns out to be, to still allow questions such as: 'Does epistemic permissibility depend on factors external to the mind?' to afford a non-trivial answer.

$$
\text { THEORY NEUTRALITY may seem pretty }
$$


straightforward. And one even may wonder whether it's worth mentioning at all. After all, won't any criterion for individuating epistemic norms satisfy it? The answer here is no. To see why, consider the following criterion, which is popular especially among epistemologists in the reliabilist camp:

GOAL INDIVIDUATION (GI). $A$ norm $\mathrm{N}$ is an epistemic norm if and only if following it is conducive to reaching epistemic goals (like truth, knowledge etc.). ${ }^{5}$

The trouble with GI is that it does not satisfy THEORY NEUTRALITY. Here is an argument by Stewart Cohen to this effect:

Evidentialists, and in particular mentalist evidentialists, hold that the justification of a belief supervenes on the internal states of the subject. It is consistent with such a view that subjects with justified beliefs are radically deceived. To say at the outset that necessarily most justified beliefs are true would disqualify mentalist evidentialism by

\footnotetext{
${ }^{5}$ Here is a characteristic expression of GI by Peter Graham:

Epistemic norms in this sense govern what we ought to say, do or think from an epistemic point of view, from the point of view of promoting true belief and avoiding error (Graham 2012).
} 
description of the subject matter $(2016,840)$.

The result is that THEORY NEUTRALITY isn't straightforward at all. In fact, there has been a growing number of epistemologists have been rather pessimistic about the prospects of satisfying this desideratum (e.g. Cohen (2016), Alston (2005) and Hazlett (2016)). In fact, Cohen and Hazlett both go on to argue that, as a result, we should eliminate 'epistemic' from our philosophical lexicon altogether. According to Cohen, we should "simply identify epistemic justification with the rationality of belief $[\ldots]$ The virtue of this approach is that we could simply dispense with the problematic technical vocabulary replacing it with a natural language expression." And here is Hazlett's recommendation:

I propose an exercise along these lines. Take any contemporary philosophical essay, and consider each use of "epistemic." I submit that each is either superfluous - in which case to be stricken - or replaceable with alternative jargon - in which case to be so replaced $(2016,547)$.

Given that several epistemologists have been pessimistic about the prospects of satisfying THEORY NEUTRALITY and have even taken this to motivate as drastic a view as eliminativism 
about the epistemic, the importance of offering an individuation criterion that satisfies this desideratum cannot be understated.

\section{Content Individuation}

With these desiderata in play, let's return to the received view in epistemology. Here it is:

CONTENT INDIVIDUATION (CI). A norm, $\mathrm{N}$, is a distinctively epistemic norm if and only if it regulates the epistemic properties required for proper phi-ing.

In more transparent talk, CI says that when we ask what the epistemic norm for phi-ing is, what we are asking is, roughly, how much warrant does one need for permissible phi-ing? One can find CI implicitly assumed in most of the literature discussing the epistemic normativity of belief, assertion or action in the last decade. ${ }^{6}$ Philosophers ask, for instance, whether justification is enough for permissible assertion/belief/action etc, or more knowledge, certainty - is needed. When they ask these questions, they take themselves to be inquiring into the epistemic norms for assertion/belief/action. Furthermore, CI is also, often enough, explicitly endorsed; take, for instance, the following passages:

\footnotetext{
${ }^{6}$ For a nice overview, see e.g. Benton (2014). For recent work see (Littlejohn and Turri 2014).
} 
[T] he problem with the agents in the above cases is that it is not epistemically appropriate for them to flatout assert that $p[\ldots]$. One reason this is clear is that the criticism of the agents concerns the grounds for their assertions. (Lackey 2013, 38)

According to Lackey, then, insofar as one is criticized for the grounds for their assertion, the criticism is warranted by a corresponding epistemic norm. Lackey makes a sufficiency claim here: according to her, criticism concerning epistemic grounds is enough for criticism sourced in an epistemic norm. Here is also Ishani Maitra:

Assertions are governed by an alethic or an epistemic norm - that is, a norm that specifies that it is appropriate to assert something only if what is asserted is true, or justifiably believed, or certain or known.” (Maitra 2011, 277).

In Maitra's view, then, when a norm stipulates an epistemic condition (justification, knowledge etc) for appropriate assertion, the norm in question is epistemic. Again, Maitra's claim is a sufficiency claim. From a different angle, Alan Hazlett makes a methodological point that points in the same direction: 
[The epistemic] is sometimes used to mean (roughly)

"of or relating to knowledge" [...]. However,

"epistemic" is sometimes used to mean (roughly) "of

or relating to belief'. (Hazlett 2016, 540)

On the face of it, CI appears to satisfy all of the desiderata. After all, CI does offer necessary and sufficient conditions for what it takes for a norm to count as distinctively epistemic as INDEPENDENCE requires. It also appears to be generalizable into a criterion for typing norms other than epistemic norms (GENERALITY). In the absence of any specific reason for thinking THEORETICAL ADEQUACY isn't satisfied, there is no direct cause for concern on this front either. Finally, it seems to make acceptable classifications: For instance, the norm that requires you to assert only what you know comes out as epistemic, as does the norm that requires you to believe only what you have evidence for. On the other hand, the norm that tells you to change a flat tire on your car doesn't. Finally, CI promises to satisfy THEORY NEUTRALITY. After all, while CI individuates epistemic norms by epistemic content it remains neutral on what counts as distinctively epistemic content. To the extent that concerns about THEORY NEUTRALITY has fueled pessimism about offering a workable criterion for individuating distinctively epistemic norms, CI holds out the hope of resisting such pessimism. 
Unfortunately, on closer inspection, there is reason to think that CI remains unsatisfactory after all. And it is not THEORY NEUTRALITY that causes trouble here. Rather, as I am about to show, CI satisfies neither THEORETICAL nor INTUITIVE ADEQUACY. I'll discuss the former first and them move on to the latter.

Recall that THEORETICAL ADEQUACY requires champions of CI to accommodate properties of norms that are widely recognized in the general theory of normativity, both for epistemic norms and in general. To assess whether CI can satisfy THEORETICAL ADEQUACY, we first need to have a quick look at what the generalized version of this criterion. The key is of course that type-specific norms in general are individuated by their content, in the relevant way. Here is a straightforward proposal for such a generalization:

CI-GEN: A norm, $\mathrm{N}$, is a norm of type $\mathrm{T}$ if and only if it regulates the properties of type T required for proper $^{7}$ phi-ing.

With CI-GEN in play, I'd now like to look at a widely-recognized property of norms in the general theory of normativity. Norms can come in conflict with each other. When this happens, one norm may override another. Moreover, there are at least two ways in which normative overriding may pan out. Here is one:

\footnotetext{
${ }^{7}$ Of course, propriety itself comes in types, i.e. epistemic, moral, prudential etc. See below for this.
} 
OVERRIDE1. Norm N1 of type T1 (moral, prudential, etc.) permits phi-ing. N1 is overridden by another norm, N2 of type T2 (moral, prudential, etc., which may but need not $=$ T1), which prohibits phi-ing, with the result that phi-ing is all-thingsconsidered improper altogether.

By way of illustration, consider a case in which you are playing chess $^{8}$ and someone shows up, puts a gun to your head and threatens to kill you unless you move the bishop horizontally. Here, doing what is permissible by the norms of chess - say, moving the bishop diagonally - is all-things-considered improper: an overriding prudential norm renders the relevant action altogether improper.

It's important to note that, while OVERRIDE1 is one way in which normative overriding can manifest itself, it isn't the only way in which this can happen. Consider:

OVERRIDE2. Norm N1 of type T1 (moral, prudential, etc.) permits phi-ing conditional on having enough of gradable property $\mathrm{P} . \mathrm{N} 1$ is overridden by another norm, N2 of type T2 (moral, prudential, etc., which may but need not $=$ T1), which

\footnotetext{
${ }^{8}$ For the purposes of this paper, I employ a very permissive sense of 'norm' to include hypothetical, as well as categorical imperatives, constitutive as well as merely conventional regulations etc. Nothing hinges on this.
} 
modifies the P-threshold for all-things-considered proper phi-ing up or down.

By way of illustration, consider a case in which you are driving down a road such that the traffic norm in place requires you to drive between 40 and $70 \mathrm{mph}$. Unfortunately for you, your kidnapper is holding a gun to your head and threatens to kill you unless you drive between 80 and $100 \mathrm{mph}$. Once again, a prudential norm overrides - in this case the traffic norm in place. Unlike in the chess case, here the overriding norm does not render the action altogether improper. Rather, what happens is that prudential requirements modify the all-things-considered proper speed up.

Here is another important property associated with overriding:

OVERRIDE-FORCE. When a norm N1 of type T1 is overridden by a norm $\mathrm{N} 2$ of type $\mathrm{T} 2$ such that $\mathrm{T} 1 \neq \mathrm{T} 2, \mathrm{~N} 1$ remains the relevant norm of type $\mathrm{T} 1$ in place.

For instance, in the above chess case, when prudential norms override the chess norm that permits you to move the bishop diagonally, this norm remains the relevant chess norm in place. In other words, the threat to your life does not change the rules of chess. Likewise, when moral/prudential norms override the traffic norm requiring you to drive between 40 and $70 \mathrm{mph}$, this 
norm remains the traffic norm in place. In other words, a threat to your life does not change the traffic norm. ${ }^{9}$

Of course, in order to satisfy THEORETICAL ADEQUACY, CI-GEN must accommodate normative overriding. That is to say, it must allow for normative overriding along the lines of both OVERRIDE1 and 2 whilst respecting OVERRIDE-FORCE. Unfortunately, there is excellent reason for thinking that CI-GEN doesn't deliver on this front. In particular, it cannot accommodate OVERRIDE2 whilst respecting OVERRIDE-FORCE. To see why not, let's return to the above case in which the operative traffic norm requires driving between 40 and $70 \mathrm{mph}$. In the case under consideration, your kidnapper will kill you unless you drive between 80 and $100 \mathrm{mph}$, with the result that the traffic norm is overridden by a prudential norm which modifies the requirement for the allthings-considered proper speed up (as per OVERRIDE2). At the same time, by OVERRIDE-FORCE, the traffic norm remains unchanged. The threat to your life doesn't change the traffic norms in place.

The trouble for CI-GEN is that it cannot accommodate this account of what is going on here. According to CI-GEN, norms are typed by the type of property they are regulating. The operative traffic norm is a traffic norm in virtue of the fact that its compliance condition features a traffic-related property, i.e.

\footnotetext{
9 Otherwise put, the traffic requirement is merely overriden rather than swamped at the context.
} 
speed. Note, though, that if driving at a speed between 40 and $70 \mathrm{mph}$ is a property pertaining to traffic, then so is driving at a speed between 80 and $100 \mathrm{mph}$. CI-GEN is thus firmly committed to holding that the norm requiring you to drive between 80 and $100 \mathrm{mph}$ in this case is also a traffic norm, in virtue of regulating a traffic-related property, i.e. speed. CI-GEN must thus hold that, in the case at hand, the threat to your life does change the traffic norm in place, contrary to OVERRIDEFORCE. As a result, CI-GEN fails THEORETICAL ADEQUACY. And that's of course bad news for CI, too.

It will come as no great surprise that CI-GEN also fails on INTUITIVE ADEQUACY. In the traffic case, for instance, the norm requiring you to drive between 80 and $100 \mathrm{mph}$ is clearly not a traffic norm. CI-GEN thus fails INTUITIVE ADEQUACY, which is already bad news for champions of CI. Furthermore, notice that the case of traffic is hardly isolated. Similar examples can be construed for many types of normativity, provided that the norms in question regulate how much of a gradable property one's phi-ing needs to enjoy in order to be permissible. It can be, for instance, morally appropriate to drive faster or slower, to have a better or a worse grade average, to wear a longer or a shorter skirt at a funeral, to speak louder or more quietly - all this, in spite of the fact that speed, grade average, skirt length and loudness of speech are not moral properties. Just because a norm regulates the appropriate length of one's skirt, it need not follow it is a fashion norm. Just because 
a norm has $\mathrm{T}$ - content, that is, it regulates a T-property, it need not follow it is a T-norm.

Finally, there is even reason to think that CI itself does little better. To see this, consider:

SING. One must: only sing songs one knows.

JUMP. One must: jump in the lake only if one knows how to swim.

TOUCH. One must: touch the wire only if one is certain that it is not live.

I submit that SING, JUMP and TOUCH are not epistemic norms. What seems much more plausible, intuitively, is that SING is an aesthetic norm while JUMP and TOUCH are prudential norms. At the same time, it is undeniable that all three norms have epistemic content, i.e. their compliance conditions feature epistemic properties. This means that CI readily classifies them as epistemic norms. Since that's at odds with intuition, there is reason to think that CI does not satisfy INTUITIVE ADEQUACY.

While CI may initially have seemed to do well when it comes to satisfying the desiderata on an adequate individuation criterion for types of norm, on reflection, it turns out that appearances are misleading. CI fails to satisfy two key desiderata, to wit THEORETICAL and INTUITIVE ADEQUACY. What's worse, the bulk of these failures are not specific to CI. Rather, the 
generalized version of CI, CI-GEN, does so too. By the same token, there is excellent reason to think that the prospects for individuating norms by their content are dim. We'll do well to look for an alternative and less problematic criterion.

Before moving on, I'd like to offer a brief diagnosis of just why CI and CI-GEN fail. The trouble with both CI and CIGEN is that the standard story about overriding in the general theory of normativity rests on a distinction between norms of a certain type, T, and non-T norms with T-content - i.e., regulating T-properties. What's going on in the problematic cases is that a norm of one type, T1 (traffic/epistemic), is overridden by a norm of a different type, T2 (moral/prudential), that has T1-related (traffic/epistemic) content and calls the shots for the all-thingsconsidered proper action. And, of course, that just couldn't be the case according to CI and CI-GEN. After all, according to these views, norms are typed by content, there cannot be distinction between a norm of type $\mathrm{T}$ and a norm with T-related content.

\section{Value Individuation}

The ambition of this section is to propose a novel way of individuating epistemic norms that improves on CI - in that it is both theoretically and intuitively adequate - and on GI - in that it is theory neutral. To lay my cards right on the table, here it is: 
VALUE INDIVIDUATION (VI). A norm $\mathrm{N}$ is of type $\mathrm{T}$ if and only if it is associated with values of type $\mathrm{T}$.

For instance, norms are prudential norms if and only if associated with prudential goods, norms are moral norms if and only if they are associated with moral goods and so on. All normative domains have goods (values) that are central to them, in virtue of the kind of normative domains they are: survival is a prudential good; promise keeping is a moral good; politeness is a social good; beauty is an aesthetic good; money is a financial good. Similarly, if etymology is a guide to what normative domain 'the epistemic' is supposed to delineate, knowledge is an epistemic good. On pain of legitimacy loss, philosophers cannot just stipulate that, starting tomorrow, they will use 'moral' to refer to a type of normative domain that does not care about promise keeping, but does care about money, or 'financial' to refer to a domain of which the chief good is safe driving. Similarly, it would be odd to count wealth and having short nails amongst epistemic goods. If all this is the case, however, it will be helpful to individuate norms by the goods associated with them, in virtue of the latter being (more) easily identifiable. ${ }^{10}$

Now, VI is still rather vague, and, on pain of intuitive inadequacy, the association relation at stake should better be

\footnotetext{
${ }^{10}$ Many thanks to XXX for pressing me on this one.
} 
spelled out in more detail. After all, one way in which a norm can be associated with a particular good is by requiring more or less thereof; this, however, of course, will get us back in the same trouble as CI: just because a norm requires me to know how to swim in order to jump in the lake, and is thereby somehow associated with an epistemic good - i.e., knowledge - it does not follow it is an epistemic norm.

The proposal here is this: the association relation stands direction of explanation: either the axiological explains the deontic, or the other way around. That is, either goods explain the norms - i.e. the norms are there in order to guide us in reaching the goods - , or the other way around, i.e. we only value the relevant goods to begin with in virtue of the associated norms. ${ }^{11}$

More about this in a short while; for now, with VI in play, let's ask how this view fares with respect to our desiderata. I take it to be obvious that INDEPENDENCE and GENERALITY are satisfied and for that reason won't discuss them in any detail here. What I'd like to focus on instead is the remaining ones, starting with INTUITIVE ADEQUACY.

\footnotetext{
${ }^{11}$ For an argument from VI to there being no epistemic norm for action, but only an epistemic norm for practical reasoning - in virtue of the latter, but not the former, being plausibly conducive to epistemic goods - see Author (Forthcoming). For a defence of the sufficiency direction of the knowledge norm of assertion via VI, see Author (2016). For an argument to the effect that VI renders the knowledge norm of assertion perfectly compatible with classical invariantism, see Author (2017).
} 
Let's start by returning to the traffic case. As a first observation, I take it that the fundamental value in the domain of traffic is the safe passage from one location to another. According to VI, then, a norm is a traffic norm if and only if it is associated with the traffic value of safe passage. In the case we were considering, driving between 40 and $70 \mathrm{mph}$ is clearly thus associated. As a result, the norm requiring you to do so is a traffic norm, which is of course the desired result. In contrast, in the case in which you face death unless you drive between 80 and $100 \mathrm{mph}$, driving at this speed is not associated with the traffic value of safe passage, especially when everyone else is bound only by the standard traffic norm. Rather, what it is associated with is a prudential value: your survival. VI thus delivers the correct result that the norm requiring you to drive between 80 and $100 \mathrm{mph}$ is a moral/prudential norm, not a traffic norm.

It is also not hard to see that the same goes for the nonepistemic norms with epistemic content that caused trouble for CI. SING, which requires you to sing only songs you know, is associated with the aesthetic value of harmony and so comes out as an aesthetic norm. JUMP, which requires you to only jump into the lake if you know how to swim, and TOUCH, which requires you only to touch the wire if you know it's not live, are associated with the prudential value of your survival, and thus are (adequately) classified as prudential norms. In this way, VI can avoid the threat to intuitive inadequacy that CI succumbs to. 
What about THEORETICAL ADEQUACY? There is reason to believe that VI also does well on this front. To return to the traffic case once more, we have already seen that the norm requiring you to drive between 40 and $70 \mathrm{mph}$ is a traffic norm and the norm requiring you to drive between 80 and $100 \mathrm{mph}$ is a prudential norm. What is going on here according to VI, then, is that the prudential norm overrides the traffic norm and calls the shots for the all-things-considered proper speed. More specifically, it modifies the all-things-considered proper speed up, just as OVERRIDE2 would have it. At the same time, it leaves the norm requiring you to drive between 40 and $70 \mathrm{mph}$ untouched. That is to say, this norm remains the operative traffic norm, in line with OVERRIDE-FORCE. As a result, VI improves on CI here, too.

Finally, let's turn to the troublesome THEORY NEUTRALITY. Recall that the association relation stands for one or another direction of explanation: either the values explain the norm, or the other way around. To see how this goes, it may be worth noting that VI is widely uncontroversial and valuetheoretically neutral in the sense that it does not come with any substantive commitments about the relation between the axiological and the deontic. That is because the association claim between norms and goals of the same type does not imply any particular direction of explanation. As a result, it is compatible with both of the two leading views on the market about the relationship between the axiological and the deontic. The 
teleologist (e.g. Moore (1903), Sidwick (1907), Slote (1989)) explains the 'ought' in terms of the 'value'; he will say that the norm of type $\mathrm{X}$ is there to guide us in reaching the value of type $\mathrm{X}$. Here is one (although, by no means, the only) ${ }^{12}$ easy teleological way to spell VI out:

VI-TEL. A norm $\mathrm{N}$ is of type $\mathrm{T}$ if and only if complying with it is conducive to acquiring values of type $\mathrm{T} .{ }^{13}$

12 In what follows, to be clear, I am only spelling VI out for illustration purposes; many more incarnations than the ones proposed are possible, of course. For instance, note that VI-TEL is explicitely formulated in ruleconsequentialist terms. Of course, a corresponding act-consequentialist way to spell it out is also available: roughly, in this case, VI-TEL would classify a norm as epistemic iff it delivers the best epistemic outcome on occasion.

13 One legitimate worry that can arise at this point concerns the sufficiency direction of VI (thanks to xxx for pressing me on this): some values are, at the same time, plausibly, of more than one type. Take, for instance, knowledge: it is plausible that, apart from it being a fundamental epistemic value, it is also likely, derivatively - a prudential value, since it promotes our survival. But then could it not be that the sufficiency claim involved in VI will mistakenly classify a prudential norm that is associated with knowledge as epistemic? The answer is 'no': VI will, indeed, classify any norm that is associated (in the relevant way, see the discussion about unpacking the association claim) with knowledge as epistemic, in virtue of knowledge being (also) an epistemic value. But that is perfectly fine. To see why, note, first, that one and the same norm can be of several types. For instance, the norm: 'Drive safely!' is a traffic norm, but also, plausibly, a prudential norm and a moral norm. Now, take, for instance, a teleological direction of explanation: say that, in virtue of knowledge being practically useful, you will have a practical norm that asks you to go to school 
In contrast, the deontologist (e.g. Scanlon (1998) Ewing (1947), Rabinowicz and Rönnow-Rasmussen (2004)) reverses the order of explanation: according to 'Fitting Attitude' accounts of value, for instance, the values of type $\mathrm{X}$ are only valuable to begin with because the norm of type $\mathrm{X}$ gives us reasons to favor them. Here is one shape this could take:

VI-DEO. A norm $\mathrm{N}$ is of type $\mathrm{T}$ if and only if it gives you reason to favor values of type $\mathrm{T}^{14}$

To see difference between the teleological and the deontological direction of explanation more clearly, consider the epistemic norm that requires you to believe only what you know. ${ }^{15}$ Let's also assume that knowledge is a distinctively epistemic value. Here is one way to spell out the teleological direction of explanation is: complying with the norm of believing only what and study hard (in order, say, to acquire lots thereof, and thereby become rich). The question is: is it fine to classify this practical norm: 'Go to school!' as also being epistemic? The correct answer seems to be 'yes'. After all, this norm is just as conducive to epistemic flourising as is, for instance, 'Follow your evidence!' (which, again, is plausibly both an epistemic and a practical norm). In fact, in virtue of the fact that, plausibly, epistemic values are generally speaking also practically and morally valuable, this should hardly be surprising. 14 For a general overview of the relevant literature in value theory, see e.g. Schroeder (2012).

15 Defended, most notably, in Williamson (2000). 
you know is conducive to acquiring knowledge. And since knowledge is an epistemic value, the knowledge norm of belief is conducive to acquiring an epistemic value and so comes out as a distinctively epistemic norm. In contrast, the deontologist does not take the norm to derive from the value. Rather, the thought here is that the norm requiring you to believe only what you know is fundamental and the fact that it gives us reason to favor knowledge explains why knowledge is a value in the first place. Since knowledge is an epistemic value, however, and since the knowledge norm of belief gives us reason to favor an epistemic value, it comes out as a distinctively epistemic norm. Crucially, in either case, the mere association claim at issue in VI holds. ${ }^{16}$

${ }^{16}$ Both the teleological and the deontological version of VI work in this case. Crucially, this is not to say that they will both work equally well in all cases. Straightforward incarnations of the teleological view, for instance, run into trouble with cases like the following, which are all too familiar from the ethics literature: Let's grant happiness is a moral value and consider a case in which you can make twenty people extremely happy by killing one scapegoat. The relevant straighforward teleological incarnation of VI would appear to predict that there is a moral norm requiring you to kill the scapegoat, which doesn't seem right. But that's not reason to think that VI isn't correct or theory neutral. Rather, it's just reason to think that the straightforward teleological incarnation of VI is false. Or take the VI-Deo verdict on SING: since SING gives one reasons to favor knowledge, it would seem to classify it as an epistemic norm. Again, this is not a problem for VI, but rather for the deontologist: teleology will just do better on this count. Importantly, VI stays neutral on which of these incarnations is the correct one. 
Since VI can be unpacked along both teleological and deontological lines, it promises to satisfy THEORY NEUTRALITY. In particular, note that even if Cohen is right and a teleological version of VI rules out evidentialist mentalism as a view about distinctively epistemic justification (because it requires conduciveness to an epistemic value), the deontological version of VI can certainly accommodate the evidentialist mentalist since it just takes the relevant norm the view espouses as fundamental and explains the corresponding value in terms of it.

\section{Conclusion}

This paper proposed a novel way to individuate epistemic norms

- Value Individuation -, and argued that the proposed individuation scheme does well in meeting a number of desiderata for any such account. In a nutshell, the proposal is to type norms by the type of good they are associated with, where the association relation is spelled out as direction of explanation.

\section{Bibliography}

Alston, W. (2005). Beyond justification: Dimensions of Epistemic Evaluation. Cornell University Press 
Author (forthcominga). Author's work.

Author (forthcoming). Author's work.

Author (2018a). Author's work.

Author (2018b). Author's work.

Author (2018c). Author's work.

Author (2017). Author's work.

Author (2016). Author's work.

Benton, M. (2014). Knowledge Norms. Internet Encyclopedia of Philosophy.

Cappelen, H. (Forthcoming). Fixing Language. Oxford University Press.

Cohen, S. (2016). Theorizing About the Epistemic. Inquiry, Vol. 59, 7-8: 839-857.

Eklund M. (2015) Intuitions, Conceptual Engineering, and Conceptual Fixed Points. In: Daly C. (eds) The Palgrave Handbook of Philosophical Methods. Palgrave Macmillan, London

Ewing, A.C. (1947). The Definition of Good, London: Macmillan.

Gerken, M (2014). Same Same but Different: The Epistemic Norms for Assertion, Action and Practical Reasoning. Philosophical Studies 168 (3):725-744.

Greenough, P. (In Progress). Against Conceptual Engineering. Book Manuscript.

Haslanger, S. (2000). Gender and race: (What) are they? (What) do we want them to be? Noûs 34 (1):31-55. 
Hazlett, A. (2016). What Does Epistemic Mean? Episteme 13 (4):539-547.

Lackey, J. (2011). Assertion and Isolated Second hand Knowledge. In Brown and Cappelen (eds.), Assertion: New Philosophical Essays. Oxford: Oxford University Press: 251-275

Littlejohn, C. and Turri, J. (2014). Epistemic Norms. Oxford: Oxford University Press.

Maitra, I. (2011). Assertion, Norms, and Games. In Brown and Cappelen (eds.), Assertion: New Philosophical Essays. Oxford: Oxford University Press: 277-296.

Moore, G.E. (1993). Principia Ethica, revised edn. Cambridge: Cambridge University Press.

Rabinowicz, W. and Rönnow-Rasmussen, T. (2004). The Strike of the Demon: On Fitting Pro-Attitudes and Value, Ethics, 114: 391423.

Scanlon, T.M. (1998). What We Owe to Each Other, Cambridge, Mass: Harvard University Press.

Scharp, K. (2013). Replacing Truth. Oxford: OUP.

Schroeder, M. (2012). Value Theory. The Stanford Encyclopedia of Philosophy (Summer 2012 Edition), Edward N. Zalta (ed.), URL = http://plato.stanford.edu/archives/sum2012/entries/valuetheory/

Sidgwick, H. (1907). The Methods of Ethics, 7th edition, Indianapolis: Hackett.

Slote, M. (1989). Beyond Optimizing, Cambridge, Mass: Harvard University Press. 
Williamson, T. (2000). Knowledge and Its Limits. Oxford University Press. 